\title{
Multidisciplinary team management of carcinoid heart disease
}

\author{
Richard P Steeds ${ }^{1,2}$, Vandana Sagar ${ }^{3}$, Shishir Shetty ${ }^{3}$, Tessa Oelofse ${ }^{4}$, Harjot Singh ${ }^{4}$, Raheel Ahmad ${ }^{1}$, \\ Elizabeth Bradley5, Rachel Moore ${ }^{4}$, Suzanne Vickrage ${ }^{6}$, Stacey Smith ${ }^{6}$, Ivan Yim ${ }^{7}$, Yasir S Elhassan ${ }^{8,9}$, \\ Hema Venkataraman ${ }^{8}$, John Ayuk ${ }^{8}$, Stephen Rooney ${ }^{7}$ and Tahir Shah ${ }^{6,10}$ \\ ${ }^{1}$ Department of Cardiology, University Hospitals Birmingham (Queen Elizabeth), NHS Hospitals Foundation Trust, Birmingham, UK \\ 2Institute of Cardiovascular Sciences, University of Birmingham, Birmingham, UK \\ ${ }^{3}$ Centre for Liver and Gastrointestinal Research, Institute of Immunology and Immunotherapy, University of Birmingham, Birmingham, UK \\ ${ }^{4}$ Departments of Anaesthesia and Intensive Care, University Hospitals Birmingham (Queen Elizabeth), NHS Hospitals Foundation Trust, Birmingham, UK \\ ${ }^{5}$ Therapy Services (Dietetics), University Hospitals Birmingham (Queen Elizabeth), NHS Hospitals Foundation Trust, Birmingham, UK \\ ${ }^{6}$ Birmingham Neuroendocrine Tumour Centre, University Hospitals Birmingham (Queen Elizabeth), NHS Hospitals Foundation Trust, Birmingham, UK \\ ${ }^{7}$ Department of Cardiothoracic Surgery, University Hospitals Birmingham (Queen Elizabeth), NHS Hospitals Foundation Trust, Birmingham, UK \\ ${ }^{8}$ Centre for Endocrinology, Diabetes and Metabolism, Birmingham Health Partners, Birmingham, UK \\ Institute of Metabolism and Systems Research, University of Birmingham, Birmingham, UK \\ ${ }^{10}$ Department of Hepatology and Liver Transplantation, University Hospitals Birmingham (Queen Elizabeth), NHS Hospitals Foundation Trust, \\ Birmingham, UK
}

Correspondence should be addressed to R P Steeds: rick.steeds@uhb.nhs.uk

\begin{abstract}
Carcinoid heart disease (CHD) is a consequence of valvular fibrosis triggered by vasoactive substances released from neuroendocrine tumours, classically in those with metastatic disease and resulting in tricuspid and pulmonary valve failure. CHD affects one in five patients who have carcinoid syndrome (CS). Valve leaflets become thickened, retracted and immobile, resulting most often in regurgitation that causes right ventricular dilatation and ultimately, right heart failure. The development of CHD heralds a significantly worse prognosis than those patients with CS who do not develop valvular disease. Diagnosis requires a low threshold of suspicion in all patients with $\mathrm{CS}$, since symptoms occur late in the disease process and clinical signs are difficult to elicit. As a result, routine screening is recommended using the biomarker, $\mathrm{N}$-terminal pro-natriuretic peptide, and regular echocardiography is then required for diagnosis and follow-up. There is no direct medical therapy for CHD, but the focus of non-surgical care is to control CS symptoms, reduce tumour load and decrease hormone levels. Valve surgery improves long-term outcome for those with severe disease compared to medical management, although peri-operative mortality remains at between 10 and $20 \%$ in experienced centres. Therefore, care needs to be multidisciplinary at all stages, with clear discussion with the patient and between teams to ensure optimum outcome for these often-complex patients.
\end{abstract}
Key Words
- neuroendocrine tumours
- carcinoid heart disease
- valvular heart disease
- surgery
- somatostatin analogues

\section{Introduction}

Neuroendocrine tumours (NETs) of gastrointestinal origin (GI NET) synthesise and release various hormones, including 5-hydroxytryptamine (5-HT). These hormones drain from the primary lesion and local lymph node metastases via the portal circulation into the liver, where they are degraded. When GI
NETs have metastasised to the liver, retro-peritoneal lymph nodes or ovaries, the hormones released by-pass degradation in the liver and gain access to the systemic circulation, causing carcinoid syndrome (CS), consisting of facial flushing, diarrhoea and occasionally bronchospasm (1). Primary NETs within the ovaries are
Endocrine Connections (2019) 8, R184-R199

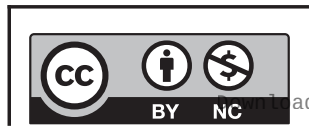

This work is licensed under a Creative Commons Attribution-NonCommercial 4.0 International License. ded from Bioscientifica.com at 04/26/2023 09:01:44AM 
uncommon but can also cause CS and CHD by direct release of bioactive amines into the inferior vena cava or renal vein. The hormones released by tumours are fibrogenic and cause scarring, most often in the rightsided heart valves, resulting in regurgitation that ultimately leads to right ventricular (RV) dilatation and dysfunction. The left sided heart valves are likely protected by inactivation of pathological substances in the lungs. Left sided heart valves can be damaged either by transit of fibrogenic amines through a patent foramen ovale, or when the primary tumour is in the lung, or when hormonal release is over-whelming (1). This entity is termed carcinoid heart disease (CHD) (2). CHD occurs in patients with advanced stages of cancer that is hormonally active. Its management is complex and challenging as patients usually present late, often with features of heart failure. Even when patients are diagnosed early, the onset and progression of CHD is unpredictable. Optimum management of the patient therefore requires close collaboration between multiple experts in order to control carcinoid and cardiovascular symptoms, quantify disease burden, determine a strategy for medical and surgical management, optimise the patient for intervention, and maximise outcomes. This article draws on our experience of managing patients with CHD, suggesting that centralising care to a limited number of centres able to invest in the required service development and having the appropriate infrastructure for multidisciplinary care may be the best way to improve outcomes for CHD patients.

\section{Pathophysiology of CHD}

In order to manage $\mathrm{CHD}$, it is vital to understand the underlying anatomy of the heart valves and how the disease alters the tissue architecture. Valve interstitial cells (VIC) are the most abundant cells in heart valves; they maintain structural integrity and are found dispersed throughout the three layers: the fibrosa, spongiosa and ventricular/atrial layers. These three layers have different compositions: the fibrosa is rich in collagen, the spongiosa is rich in proteoglycans and the ventricular/atrial layer is dense in elastin. These layers are then covered by valve endothelial cells (VEC) (Fig. 1) (3). Studies have shown that an accumulation of VICs associated with inflammatory cells, neovascularisation, increased matrix production and eventually fibrosis and calcification, occurs in response to valvular injury (4). In diseased valves, VICs become activated to regulate repair and valve remodelling (5).

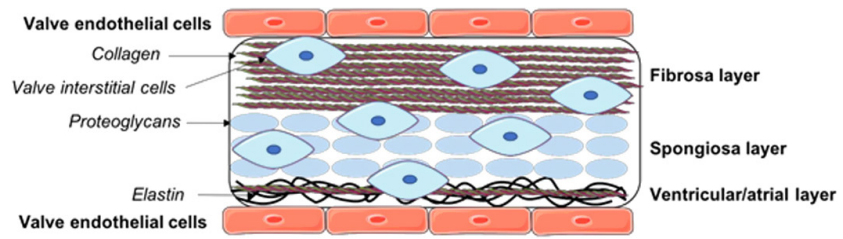

Figure 1

Schematic diagram illustrating the valve layers.

There are five different phenotypes in the VIC group: embryonic progenitor endothelial/mesenchymal cells, quiescent VICs (qVICs), activated VICs (aVICs), progenitor VICs (pVICs) and osteoblastic VICs (obVICs) (6). The embryonic progenitor endothelial/mesenchymal cells undergo endothelial-to-mesenchymal transformation (EMT). Individual endothelial cells then migrate into the endocardial cushion resulting in the transformation of endothelial cells into mesenchymal cells, and matrix remodelling occurs in the cushion to develop into mature heart valves $(6,7)$. It is thought that the EMT process also occurs after post-natal development in adult valves following injury and valve disease. The VECs on the cushion surface contain properties of the valve progenitor cells and may result in VICs formation which then participate in valve repair (8).

The qVICs are in the heart valve leaflet, maintain valve structure and function, and generally keep the valve avascular by inhibiting angiogenesis. In response to valve injury, qVICs become activated and also give rise to aVICs to enable valve repair and remodelling to take place (4). The pVICs are valvular stem cells derived from various origins and are found in the bone marrow, circulation, and heart valve leaflet. They consist of two cell types: endothelial progenitor cell (EPC) and dendritic cell (DC). EPC is identified by the stem cell markers CD133 and CD34, are highly proliferative and are able to form new blood vessels $(6,9)$. DCs are identified by the intracellular Ca-binding protein, S100 (8). In response to injury, pVICs including the circulating cells, bone marrow-derived cells and the resident valvular progenitor cells are another source of aVICs. The aVICs responding to valve injury and disease take on characteristics of myofibroblasts but are not smooth muscles as they have incomplete basement membranes (10). These cells are located in the heart valve leaflet. The aVICs are positive for $\alpha$-smooth muscle actin ( $\alpha$-SMA) and lead to increased extracellular matrix production and degradation, MMP expression and tissue inhibitors of MMP expression, as well as increased proliferation and migration. These are all important factors in the repair process. These VICs also increase the
This work is licensed under a Creative Commons Attribution-NonCommercial 4.0 International License. ed from Bioscientifica.com at 04/26/2023 09:01:44AM via free access 
secretion of cytokines, particularly transforming growth factor $\beta$ (TGF- $\beta$ ) (6). The majority of aVICs are then discarded by apoptosis after remodelling has occurred (11). When this process is dysregulated, aVICs survive resulting in abnormal extracellular matrix production and remodelling, pathological fibrosis, angiogenesis and neovascularisation and calcification, eventually leading to valve disease $(6,11)$. The obVICs are also located in the heart valve leaflet too and may be derived from pVICs. They actively participate in the calcification process, and also cause chondrogenesis and osteogenesis in the heart valve (6).

NETs secrete a range of vasoactive substances, including 5-HT, prostaglandins, bradykinin, histamine, and substances containing fibroblast proliferative properties (such as substance P) or TGF $\beta$ that are thought to be involved in the pathogenesis (12). 5-HT receptors play a major role in the development of CHD. These are present in the heart, with subtype 5-HT2B receptor being predominant (13). Activation of these receptors results in mitogenesis of fibroblasts and smooth muscles cells, cytokine recruitment, and upregulation of TGF $\beta$. Another factor involved in the pathogenesis of this disease is deficiency of the 5-HT transporter which is involved in the uptake of 5-HT and inactivation in the lungs (2).
This complex process results in the deposition of endocardial plaques, plaques in the chordae, papillary muscles and heart chambers, and occasionally within the vascular intima, including the pulmonary arteries and aorta (12). These plaques comprised myofibroblasts, smooth muscle cells, extracellular matrix components including collagen, elastin and myxoid matrix, and an endocardial cell layer (14). Classically, plaques involve the right side of the heart (around 90\% of cases), likely due to pulmonary inactivation of the vasoactive substances, resulting in right heart failure.

\section{Presentation, clinical assessment and diagnosis}

Cardiac symptoms and signs are often lacking or are subtle until CHD is advanced. Clinical examination lacks sensitivity in detecting valvular heart disease and is particularly poor in detection of the right-sided lesions that are common in CS, so should not be relied upon for screening of patients (15). Electrocardiography (Fig. 2) and chest radiography (Fig. 3) are also unhelpful in the majority of patients with $\mathrm{CHD}$, as changes are non-specific and often only detect advanced disease. N-terminal pro-B-type

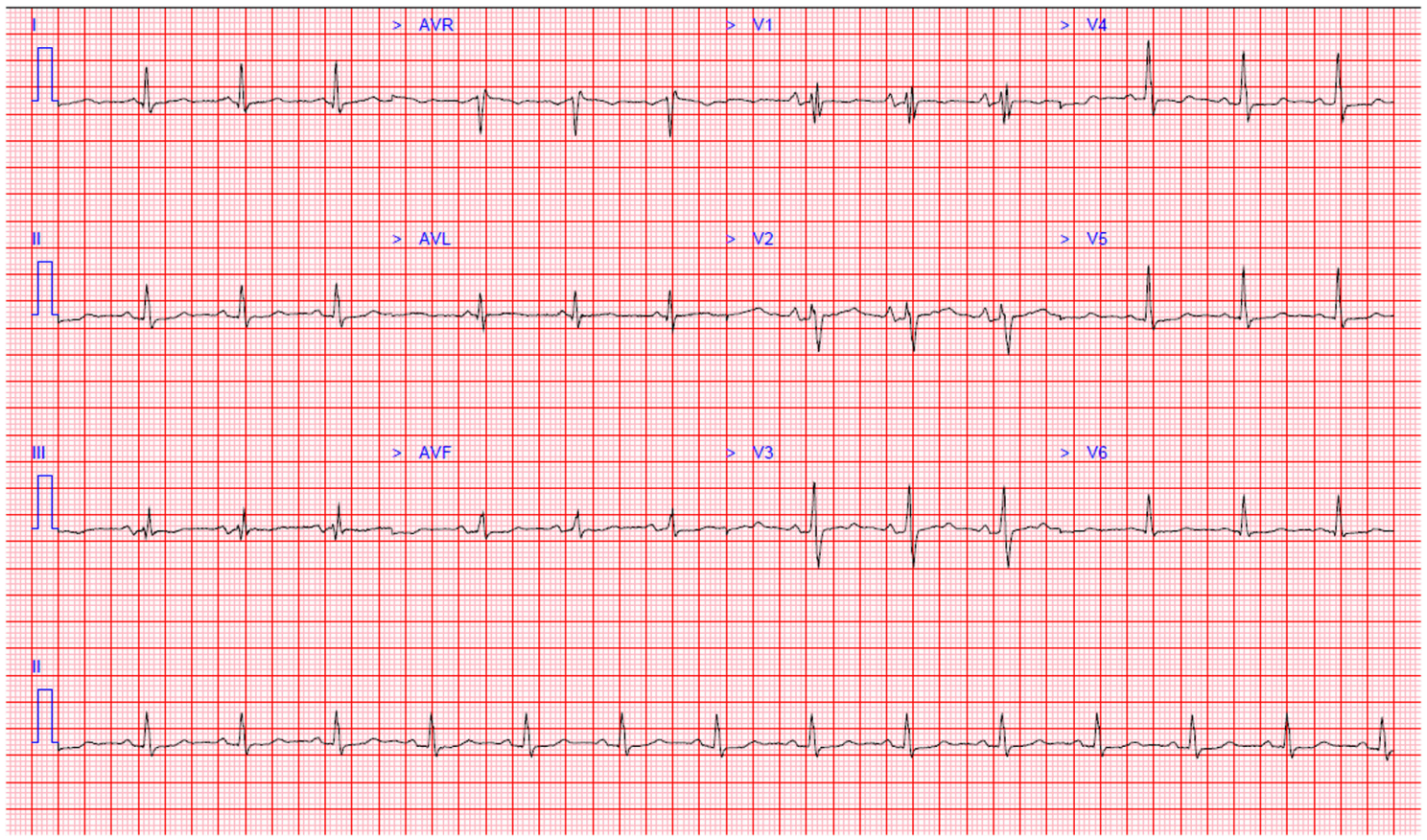

\section{Figure 2}

Electrocardiogram of a 75-year-old male who was diagnosed with GI-NET 5 years after developing symptoms. He presented with active weight loss, severe diarrhoea and flushing. At the time of presentation, the patient had severe tricuspid regurgitation, severe pulmonary regurgitation, with right ventricular dilatation and impairment. His resting 12-lead ECG demonstrate sinus rhythm with normal axis but ECG criteria for incomplete right bundle branch block with an rSR complex in V1.

This work is licensed under a Creative Commons Attribution-NonCommercial 4.0 International License. ded from Bioscientifica,com at 04/26/2023 09:01:44AM 


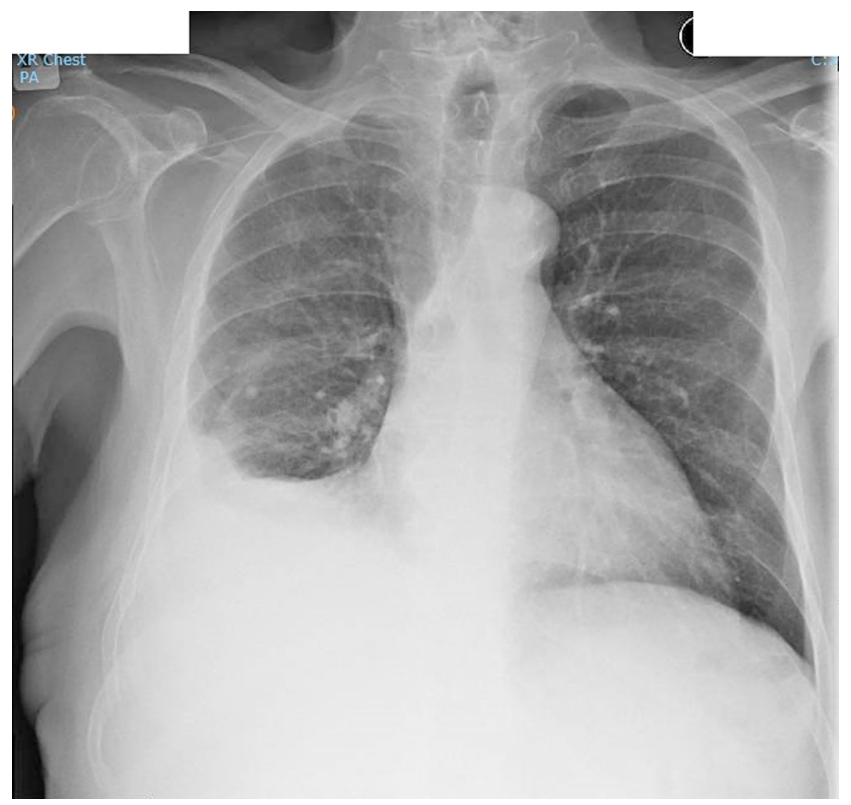

\section{Figure 3}

Chest radiograph of a 74-year-old male who was diagnosed with GI-NET in 2015 and found to have elevated NT proBNP, which was attributed to age and hypertension without evidence of $\mathrm{CHD}$. He remained under follow-up, developing tricuspid regurgitation that became severe and was associated with breathlessness. He was found, however, to have a right pleural effusion that was exudative, without cellular infiltrate and with normal high-resolution computed tomogram and with normal thoracoscopy.

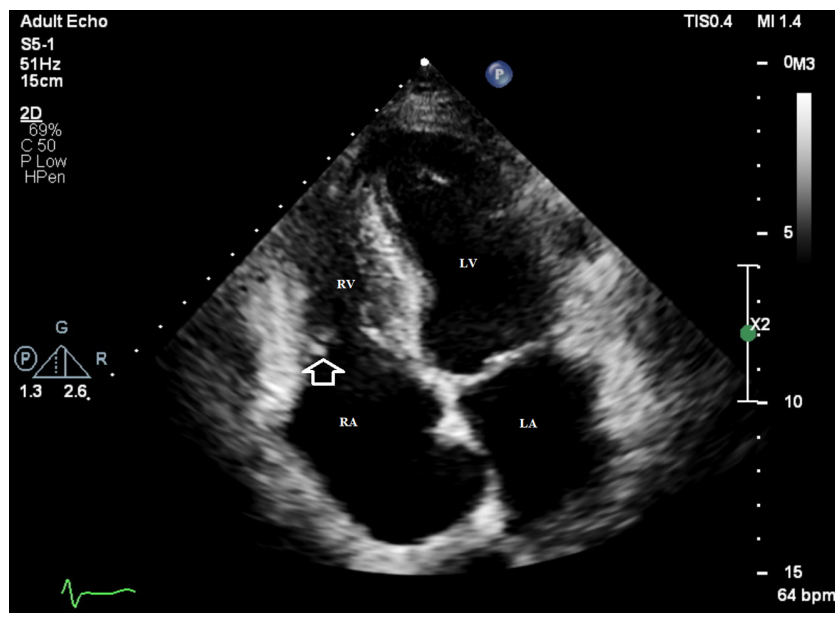

Figure 4

Apical four-chamber view from a transthoracic echocardiogram demonstrating the hallmark features of thickening, restriction of motion and retraction of the tricuspid valve leaflets, indicated by the arrow. The image has been frozen at end-systole, before the atrio-ventricular valve leaflets should be open but, in this case, the tricuspid valve leaflets are clearly open at a time when the mitral valve leaflets are closed. LA, left atrium; LV, left ventricle; RA, right atrium; RV, right ventricle. natriuretic peptide (NT-proBNP) is a useful biomarker that should be checked in all patients with CS on a 6-monthly basis, and a cut-off level of $260 \mathrm{ng} / \mathrm{L}$ has reasonable sensitivity for screening patients with a high negative predictive value (16). NT-proBNP is a product of cleavage of a pro-hormone released predominantly from myocardial cells mainly in the atria in response to volume expansion (chamber dilatation) and increased wall stress, so it is not specific to CHD and may be elevated in patients with other co-morbidity, for example arrhythmia (atrial fibrillation) and coronary artery disease. Therefore, any patient with an elevated NT-proBNP should then undergo transthoracic echocardiography (TTE), which is the main modality for diagnosis of CHD (Fig. 4). Although scoring systems have been developed to improve accuracy of diagnosis on TTE, this is a technique that relies on the skill and experience of the operator in identifying the changes of CHD (17). Therefore, in early cases when changes may be limited to loss of normal concave curvature of leaflets and mild thickening, diagnosis can be missed unless the operator is experienced and it may be useful to obtain reviews from those experienced in imaging patients with CHD.

Unfortunately, screening for CHD is frequently forgotten on initial presentation of patients with NET, or regular, repeat assessment then neglected (18). As a result, NET patients with $\mathrm{CHD}$ often present late with advanced disease. Symptoms include a gradual reduction in exercise capacity, which is often wrongly attributed (by patients and physicians alike) to other things, such as ageing, the effects of metastatic NET or therapy thereof, until the development of signs of right heart failure, commonly swelling of the ankles. The tricuspid valve (TV) is affected in most patients, with the classical changes seen on 2D TTE including leaflet thickening, retraction, and reduction in mobility, usually resulting in regurgitation (TR) but sometimes with co-existing stenosis (Fig. 5). The pulmonary valve (PV) is involved in half of those with CHD, again most often with regurgitation (PR) but also occasionally with co-existing stenosis (19) (Fig. 6). By the time of presentation, the consequence of chronic, severe TR is right ventricular dilatation and dysfunction. TTE is the default modality for diagnosis, quantifying severity of valve lesions and measurement of the effects on the right ventricle (RV). Transoesophageal echocardiography (TOE) can be of added benefit when TTE views are suboptimal, particularly with the use of $3 \mathrm{D}$ to provide high-quality imaging of the PV where all three cusps cannot be visualised on $2 \mathrm{D}$ alone. $3 \mathrm{D}$ TOE can improve visualisation of structural tricuspid valve defects (20) (Fig. 7). 


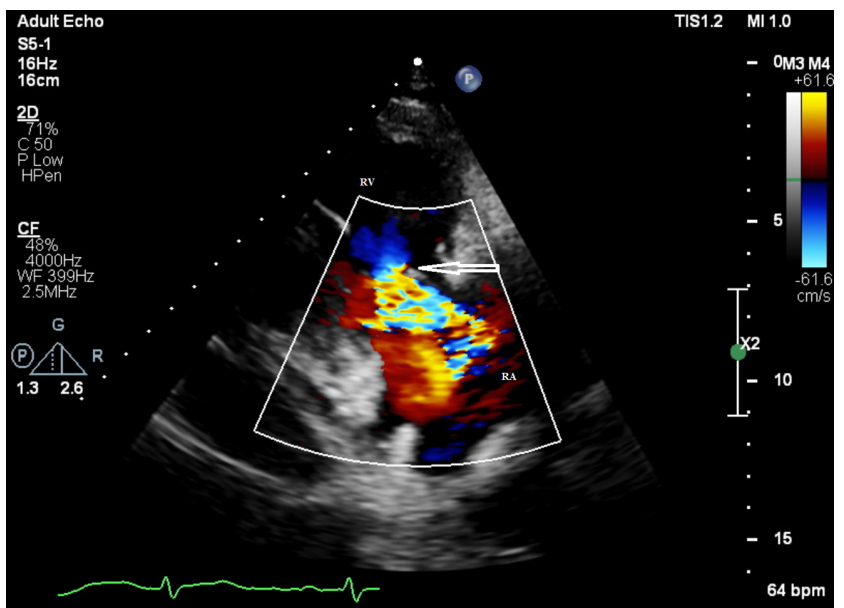

Figure 5

Tilted parasternal long axis view from a transthoracic echocardiogram using colour Doppler to demonstrate severe, central tricuspid regurgitation into the right atrium due to carcinoid heart disease. RA, right atrium; RV, right ventricle.

Left-sided valve disease affects a minority of patients, limited to those with a patent foramen ovale (PFO) that allows blood to avoid passage through the lungs, those with pulmonary metastases, and those with high tumour burden who may secrete such large volume of hormones that these overcome lung clearance (21). Diagnosis of a PFO requires agitated saline TTE to detect early passage of contrast from the right side of the heart to the left, which is vital in pre-surgical assessment to ensure closure at the time of operation (Fig. 8).

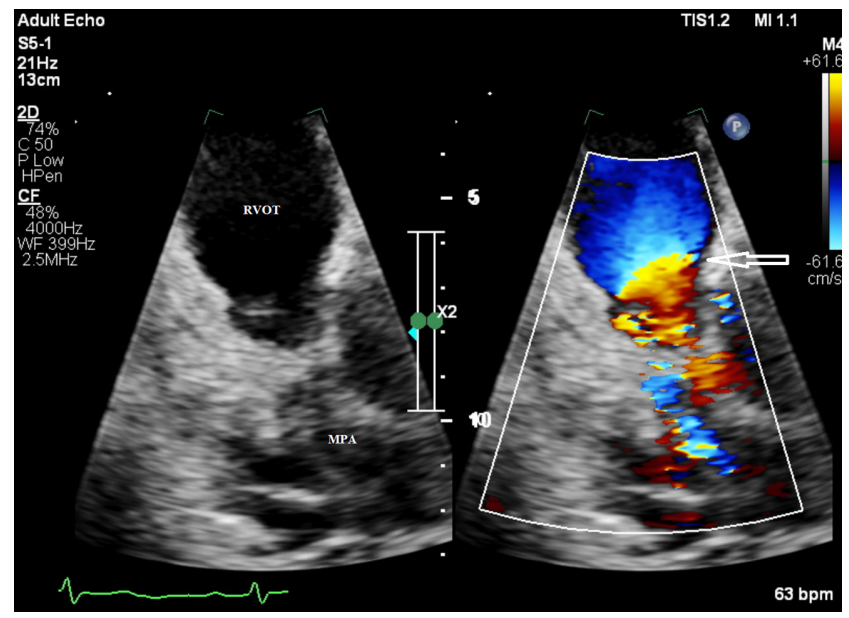

Figure 6

Tilted parasternal long axis view from a transthoracic echocardiogram using 2D (left panel) and colour Doppler (right panel) in a side-by-side format to demonstrate flow acceleration (indicated by the arrow) through fixed, retracted pulmonary valve leaflets, with the branch pulmonary arteries at the bottom of the image. MPA, main pulmonary artery; RVOT, right ventricular outflow tract.

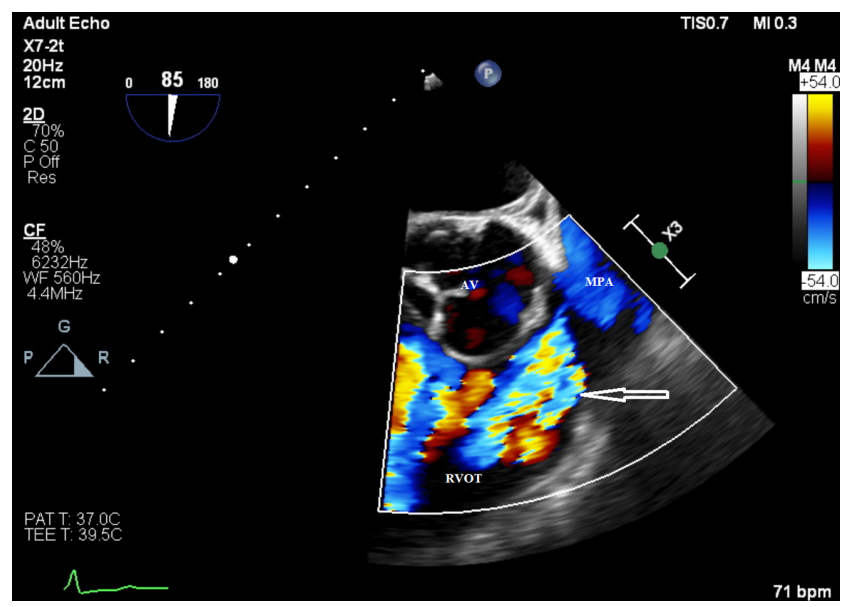

Figure 7

Mid-oesophageal long axis view of the pulmonary valve from a transoesophageal echocardiogram using colour Doppler to demonstrate severe pulmonary regurgitation (indicated by the arrow) that could not be identified in a 73-year-old ex-smoker with limited transthoracic acoustic window. AV, aortic valve; MPA, main pulmonary artery; RVOT, right ventricular outflow tract.

In those patients diagnosed with CHD that is not severe, review should be performed on a 6-monthly basis, as progression of valve disease is not linear and can be rapid (22). Faster progression of CHD is more likely in those with clinical and biochemical evidence of active CS, although radiological burden of NET does not appear to be associated with advancing CHD. Moller et al. found that progression

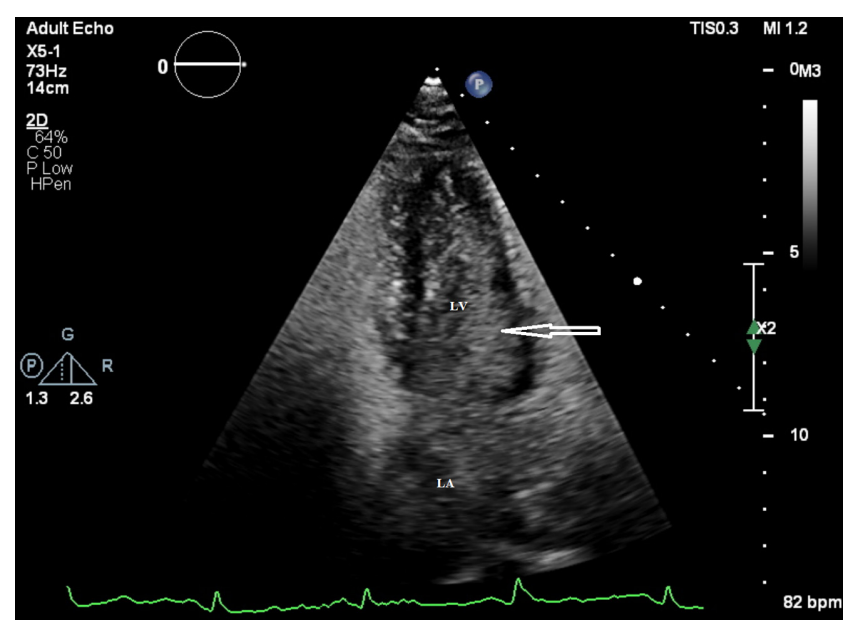

Figure 8

Agitated saline contrast transthoracic echocardiogram from the apical four-chamber view after release of Valsalva, with contrast seen in the left ventricle within three RR cycles from injection (the arrow indicates the ultrasound reflected from agitated saline giving the 'white' appearance within the ventricular cavity, compared to the black myocardium adjacent). This was a large patent foramen ovale in a 58-year-old female with symptomatic severe tricuspid regurgitation and right-to-left shunting at rest resulting in hypoxia that required device closure. LA, left atrium; $\mathrm{LV}$, left ventricle.

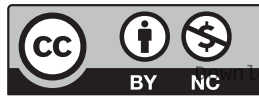

This work is licensed under a Creative Commons Attribution-NonCommercial 4.0 International License. ded from Bioscientifica.com at 04/26/2023 09:01:44AM 
of CHD was proportionately faster for each $25 \mathrm{mg}$ increase in urine 5HIAA and also faster in those who had received prior cytotoxic chemotherapy, although the latter may have been a marker for those with more aggressive disease (23). Bhattacharyya et al. found that those with urine 5HIAA levels $>300 \mu \mathrm{mol} / 24 \mathrm{~h}$ or active flushing more than three times per day likewise had an increased risk of progression (24). Likewise, Dobson et al. also found faster progression in those with unstable symptoms, defined by a $>50 \%$ increase in frequency of flushing or bowel movements, and each increment $>100 \mathrm{nmol} / \mathrm{L}$ in plasma 5HIAA (22). In those with established CHD, TTE should be considered every 6 months, although alternating with cardiovascular magnetic resonance (CMR) imaging can be advantageous when tracking change in RV size and function, since this is more reliable and reproducible than 2D or 3D TTE $(22,25)$ (Fig. 9). There are no therapies that directly retard or reverse the progression of $\mathrm{CHD}$, but there is indirect evidence from the reduction in rate of CHD since the introduction of somatostatin analogues and the factors associated with faster progression that reduction in CS activity is likely to be important. It is not known whether there is a 'threshold target' for lowering 5HIAA to minimise progression of CHD but suppression of active flushing and stability of bowel movements may be a reasonable aim.
Recommendations on presentation, clinical assessment and diagnosis:

1. Presentation of patients with CHD is highly variable but is often late.

2. Clinical examination is not a reliable way of screening for CHD.

3. All patients with raised plasma/urine 5HIAA should be screened annually for CHD.

4. Screening should be with NT proBNP and those with levels $>260 \mathrm{ng} / \mathrm{L}$ should undergo transthoracic echocardiography.

5. Patients with CHD should be referred to a Cardiologist and seen every 6 months.

\section{Medical management of CHD}

Treatment of CHD should be multidisciplinary, as there are competing demands of both CHD and NET. In some patients, surgery for CHD may be the priority to ensure the survival and fitness of the patient to then pursue more aggressive treatment of the NET. In others, however, the patient may need stabilisation of CS with reduction of tumour load before surgery for CHD can be more safely undertaken.

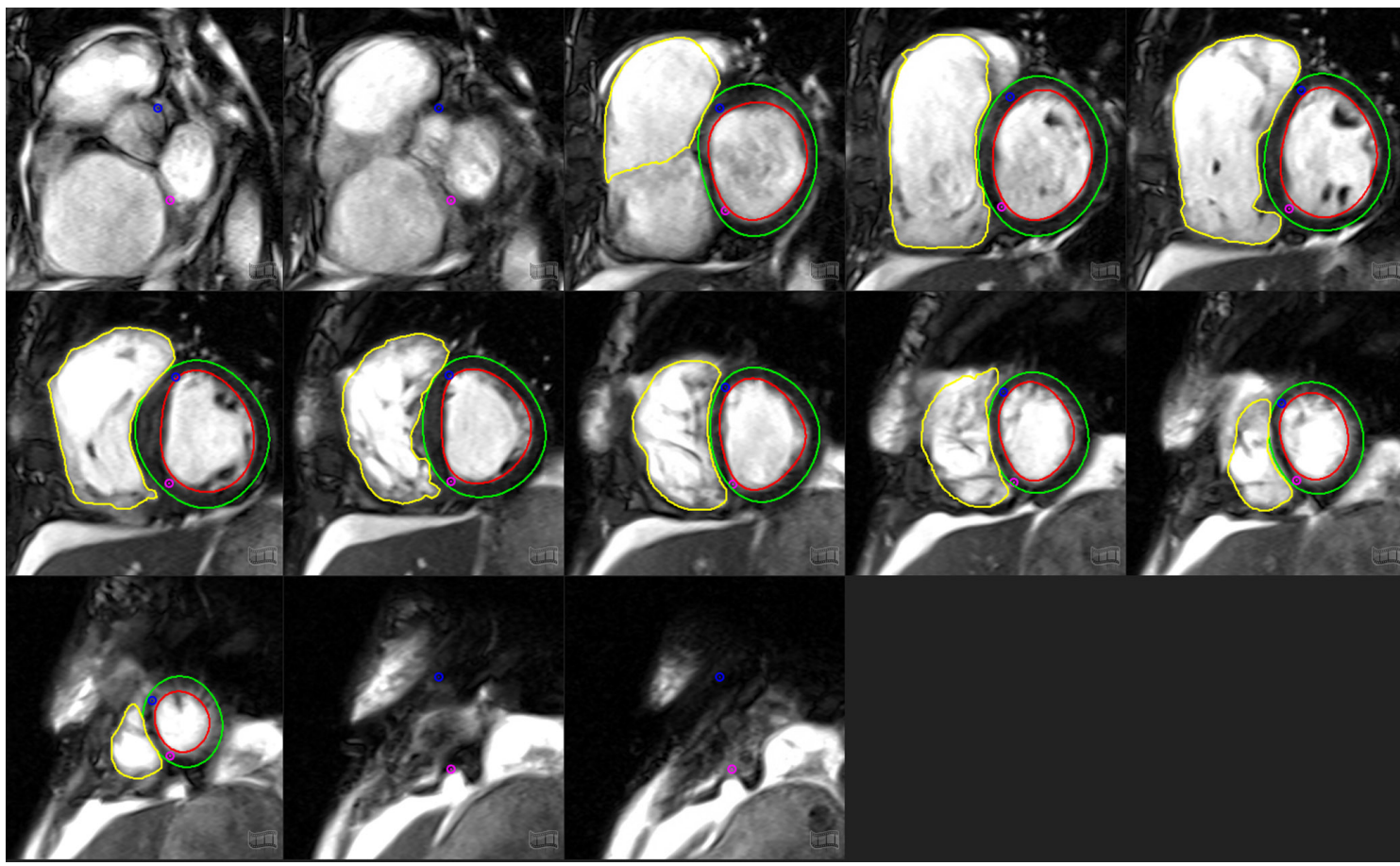

Figure 9

A contiguous stack of short axis steady-state free precession cine images is acquired through the long axis of the left and right ventricles, with annotation to demonstrate endocardial delineation from which end-diastolic (and end-systolic volumes: not shown) volumes are created.

https://ec.bioscientifica.com https://doi.org/10.1530/EC-19-0413 (c) 2019 The authors Published by Bioscientifica Ltd

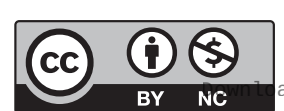

This work is licensed under a Creative Commons Attribution-NonCommercial 4.0 International License. ded from Bioscientifica.com at 04/26/2023 09:01:44AM 


\section{Pharmacotherapy for CHD and CHF}

Once patients have developed effort intolerance or signs of right heart failure, the introduction of a thiazide or loop diuretic is usually beneficial to improve exercise intolerance and reduce peripheral oedema and ascites. Any improvement should neither be taken as a sign that all is well, nor that further action can be delayed, as the period during which the patient will remain stable is of variable duration and this time should be used to assess the patient for valve surgery. There is no evidence of benefit of standard heart failure therapy such as angiotensin-converting enzyme inhibitors, angiotensinreceptor antagonists or beta-blockers in RV dilatation and dysfunction in CHD. Moreover, treatment of RV failure in the context of right heart valve failure is difficult, as depletion of intravascular volume and pooling due to hypotension can further impair cardiac output.

\section{Management of carcinoid syndrome}

CS is best treated starting with somatostatin analogues (SSAs) in the form of long-acting preparations Sandostatin $\operatorname{LAR}^{\circledR}$ or Lanreotide autogel ${ }^{\circledR}$. These are given every 4 weeks and are effective in improving CS by reducing the release of hormones, such as 5-HT, by tumour cells. While these agents are of great use in patients with CS, there are no data to suggest that these either cause regression or prevent progression of CHD, and no evidence of improvement in survival in CHD (23). By the time of onset of CHD, standard dosages of SSAs begin to lose efficacy in managing symptoms. At this point, the frequency of injections should be increased from the standard 4 weekly to 3- or 2-weekly. Short-acting octreotide given subcutaneously 3 times daily can provide additional relief. If these measures are not enough, then the following steps can be considered (Table 1).

1. Intravenous octreotide starting at $50 \mu \mathrm{g} / \mathrm{h}$ and increasing to $500 \mu \mathrm{g} / \mathrm{h}$ if required.

2. Alpha interferons, although highly effective in some patients at improving CS symptoms, can be difficult to obtain. While they may be of use in patients with CS, there are no data to suggest that alpha interferons either cause regression or prevent progression of $\mathrm{CHD}$, and no evidence of improvement in survival in CHD.

3. Telotristat ethyl ( $250 \mathrm{mg} \mathrm{tds}$ ) is approved for diarrhoea related to CS and works by inhibiting tryptophan hydroxylase, thereby reducing 5-HT biosynthesis. There is evidence of efficacy in reduction in urinary 5-hydroxyindoleacetic acid and in control of CS and is used for this indication but without evidence relating to stability of CHD itself (26).

4. Trans-arterial embolisation (TAE) can be used with caution in the presence of RV failure. It may be safer to perform TAE piecemeal, with anaesthetic cover and recovery in HDU/ITU.

5. Surgical Reduction of Tumour Burden in NETs. Surgical resection of the primary tumour and removal of hepatic metastases can be an option in the few patients who do not have a high burden of liver disease. While such surgery can be useful both in preventing progression of CHD and improving prognosis, surgery on the liver is usually precluded in the presence of right heart failure (27).

Table 1 Management of carcinoid syndrome in the patient with carcinoid heart disease.

Intervention

Additional octreotide

Interferon alpha (alone or in addition to somatostatin analogues) (66)

Telotristat (in addition to somatostatin analogues) (26)

TACE (in addition to medical NA therapies)

Lutetium peptide receptor targeted radionuclide therapy (Lu-PRRT) (67)

\section{Dose}

Given to optimise CS control as either 50-100 $\mu \mathrm{g} / \mathrm{h}$ i.v. or 50-500 $\mu \mathrm{g}$ tds s/c

Pegasys ${ }^{\circledR} 90-180 \mu \mathrm{g} /$ week (other types and preparations of Interferon are no longer available in UK) $250 \mathrm{mg}$ tds

$7000 \mathrm{MBq} \times 4$ given at approximately 8 weekly intervals

\begin{tabular}{l} 
Advantages \\
\hline Provides additional \\
control of CS symptoms. \\
It is easy to administer \\
and adjust \\
Reduces hormone \\
secretion by tumours \\
and CS symptoms \\
Inhibits 5-HT synthesis, \\
reduces 5HIAA levels and \\
improves diarrhoea \\
Immediate and lasting \\
improvement in 5HIAA \\
levels and CS symptoms \\
Excellent improvement in \\
PFS and OS
\end{tabular}

Disadvantages

Frequent injections can become uncomfortable when administered s/c

Only tolerated or effective in about half the patients. Declining availability

Role in reducing carcinoid crisis not evaluated yet

Significant morbidity and mortality that is possibly worsened by right heart failure Only improves 5HIAA levels and CS symptoms sometimes. Takes 8-10 months for a course of treatment https://ec.bioscientifica.com

https://doi.org/10.1530/EC-19-0413 (c) 2019 The authors Published by Bioscientifica Ltd
This work is licensed under a Creative Commons Attribution-NonCommercial 4.0 International License. ed from Bioscientifica.com at 04/26/2023 09:01:44AM 
High right heart pressures as seen in severe TR increase the risk of bleeding intra-operatively owing to the increase in back pressure through the valve-less venous system of the liver. Furthermore, high right heart pressures can also hamper venous outflow and may compromise the ability of the liver to regenerate after surgery. Surgical reduction in tumour load by operating on other areas responsible for CS, however, such as the ovaries, may be possible. Liver surgery may become feasible after valve replacement.

\section{Nutrition: optimising the patient for surgery}

Key factors in our experience which influence 30-day outcome following surgery have been control of CS symptoms (see earlier) and ensuring optimisation of nutrition with stabilisation of weight. This is a key facet of the involvement of the NET specialists in the pre-operative optimisation of the patient, and either instability in CS or an active catabolic state would be reasons accepted for delay in cardiothoracic surgery. There is a high prevalence of malnutrition amongst cancer patients, and this is associated with poorer outcomes and reduced survival (28). Studies have shown that $28-58 \%$ of patients with NETs are at nutritional risk, with higher incidence in those with a GI-NET compared to those with bronchial NET (26). It is widely understood that malnutrition is associated with poorer outcomes in terms of increased complication rates postsurgery, increased length of stay, decreased response to treatment, higher in-patient mortality and poorer quality of life (29).

The cause of malnutrition in patients with NETs is likely to be multifactorial and may include reduced oral intake, malabsorption, diarrhoea and increased total energy expenditure. Patients with a poor oral intake should be offered individualised dietary assessment and counselling and may require oral nutritional supplements or possibly artificial nutrition support. It is thought that sarcopenia and thus reduced muscle mass rather than loss of fat mass, has the greatest impact on outcomes in patients with cancer. It therefore seems prudent to ensure patients are achieving an optimal protein intake, with attention paid to protein distribution and frequency of ingestion as these have been shown to play an important role in preserving muscle mass and function, with a recommended protein target of 1-1.5 g/kg/day (30). Niacin (Vitamin B3) deficiency affects a quarter of patients with CS owing to increased tryptophan metabolism for serotonin production, and supplementation of $25-50 \mathrm{mg}$ a day is therefore recommended in patients with CS (31). Where patients are experiencing symptoms suggestive of malabsorption such as diarrhoea, steatorrhea, borborygmi, flatus, bloating and pain after eating, measures should be taken to identify and treat the cause of this. Nutritional support in the presence of untreated malabsorption is likely to be futile. A summary of nutritional recommendations is listed in Table 2.

\section{Recommendations on medical management of CHD:}

1. There are no current non-invasive treatments for CHD.

2. Diuretics improve symptoms but pharmacotherapy is palliative.

3. Control of carcinoid symptoms and suppression of plasma/serum/urine 5HIAA should be a focus in those with $\mathrm{CHD}$, usually requiring high-dose somatostatin analogue therapy.

4. Patients under consideration for surgery for CHD need to be in an optimal nutritional status and formal dietetic input is required.

\section{Surgery for CHD}

\section{Indications for surgery}

The current accepted indications for valve replacement include severe valve regurgitation or stenosis with symptoms of effort intolerance or right heart failure (2). Rarely, patients have had valve surgery in our service in preparation for potentially curative resection of primary and metastatic disease or for major palliative intervention. Given that patients will usually be on intensive care for 24-48 h, in hospital for 7-10 days, but will then take 6-12 weeks to recover from surgery, the expectation is that those who go through surgery should have a life expectancy of at least 12 months. Once patients are symptomatic with $\mathrm{CHD}$, prognosis deteriorates quickly and peri-operative risk increases with delay, so our practice is to admit patients as soon as possible for work-up and review over 1 week. The patient's case is then discussed within a multidisciplinary meeting involving Cardiologist, Cardiothoracic anaesthetist, Cardiothoracic surgeon, NET physician and NET specialist nurse all experienced in the field of CHD. Valve surgery should then be performed as quickly as is feasible, once any hurdles are overcome, the main ones being control of CS, nutrition, and physical disability.

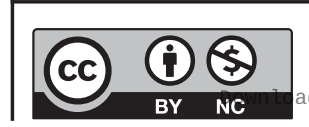

This work is licensed under a Creative Commons Attribution-NonCommercial 4.0 International License. ded from Bioscientifica.com at 04/26/2023 09:01:44AM via free access 
Table 2 Nutritional management in CS and CHD.

All patients with NETs should be screened for risk of malnutrition.

Patients with stable weight, muscle mass and good function who are eating well should be advised to follow a healthy, balanced diet.

All patients who are at nutritional risk should be provided with specialist nutrition support.

Where oral nutritional intake is inadequate patients should be offered artificial enteral nutrition support (tube feeding). Where enteral nutrition is not appropriate or feasible patients should be considered for parenteral nutrition.

All patients with NETs should be screened for malabsorption and measures should be taken to normalise digestion where possible.

\section{Choosing the patient for surgery}

Cardiothoracic surgery to replace valve disease is the only effective treatment for advanced CHD but causes morbidity, requires time for recovery and continues to carry a significant risk of death within 30 days. At present, transcatheter techniques have not been used to treat CHD of native valves although their use is increasing in other aetiologies (32). Although early reports suggested very high peri-operative mortality during surgery for CHD, serial data have suggested improved outcomes over time in centres with experience and 30-day mortality is now much lower $(33,34)$. A series of studies have published results in this area that are summarised in Table 3, which reflect that as with all cardiovascular intervention, outcomes improve with increased knowledge about the disease and with volume of procedures performed $(35,36$, $37,38,39,40,41,42,43,44)$. Those patients who proceed with surgery have a 1 -year survival of $75 \%$ compared with $45 \%$ for those who have an indication for surgery for CHD but do not proceed (33). There is a lack of data that identifies those at greatest risk of major morbidity and mortality within 30 days of surgery but in our experience, those factors which are particularly important in deciding which patients will survive include age, failure of the RV after TV replacement (which removes the 'offloading' of a failing ventricle), haemodynamic instability from uncontrolled CS, and on-going weight loss before surgery. Although data are not available specifically from peri-operative outcomes in NET-CHD patients, there are extensive data highlighting both weight loss and low serum albumin as predictors of worse outcomes following general surgery (45). There are data on surgical outcomes in patients with pancreatic cancer that survival was reduced in those with weight loss of more than $10 \%$ (46). In our practice, we consider a weight loss of $10 \%$ compared to stable pre-illness weight to be significant in NET-CHD.

A list of factors taken into consideration by the team is outlined in Table 4 .

\section{Valve surgery}

Surgery primarily involves replacement of any valve with severe regurgitation or stenosis, together with closure of PFO if present. Given the unpredictable rate of progression of CHD, replacement of moderately affected valves is also usually carried out at the same sitting, although this decision is a balance between increased risk of prolonged surgery against the risk of potential progression if a valve is left untouched. Rarely, patients can have all four valves

Table 3 Surgical outcomes in NET-CHD.

\begin{tabular}{|c|c|c|c|c|}
\hline Author & Recruitment & Number & Age & \\
\hline Robiolio & 1972-1994 & 8 & $60(33-76)$ & \\
\hline Connollyb & 1985-1992 & 26 & $54(25-72)$ & \\
\hline Moller ${ }^{b}$ & $1981-2000$ & 87 & $57(50-64)$ & \\
\hline Castillo & $2001-2006$ & 10 & $59 \pm 9$ & \\
\hline Bhattacharyya & 2006-2010 & 22 & $60(50-65)$ & \\
\hline Komoda & 2000-2008 & 12 & $64(56-69)$ & \\
\hline Mokhles & 1993-2010 & 19 & $56 \pm 10$ & \\
\hline Connollyb & 1985-2012 & 195 & $61 \pm 11$ & 20 \\
\hline Kuntze & 2008-2014 & 39 & $66(28-84)$ & \\
\hline Edwards & 2005-2015 & 32 & $68 \pm 8$ & \\
\hline Yong & $2012-2016$ & 20 & $64(29-77)$ & \\
\hline Mujtaba & $2011-2016$ & 9 & $61(55-70)$ & \\
\hline \multicolumn{5}{|c|}{$\begin{array}{l}\text { Data are mean } \pm \text { S.D., median ( } 25-75 \text { th percentile), absolute }(\%) \text {. } \\
\text { aAfter 2000; 'Single centre series at different time points } \\
\text { CC, carcinoid crisis; HPS, hepatorenal syndrome; LF, liver failure; NA, not avai }\end{array}$} \\
\hline \multicolumn{2}{|c|}{$\begin{array}{l}\text { https://ec.bioscientifica.com } \\
\text { https://doi.org/10.1530/EC-19-0413 }\end{array}$} & \multicolumn{3}{|c|}{$\begin{array}{l}\text { (c) } 2019 \text { The authors } \\
\text { d by Bioscientifica Ltd }\end{array}$} \\
\hline
\end{tabular}

\begin{tabular}{|c|c|c|c|}
\hline $\begin{array}{l}\text { 1-year } \\
\text { survival }\end{array}$ & $\begin{array}{l}\text { 5-year } \\
\text { survival }\end{array}$ & Follow-up & Complications \\
\hline $37 \%$ & $31 \%$ & Up to 12 years & \\
\hline $32 \%$ & NA & NA & RVF; Bleeding \\
\hline NA & NA & & \\
\hline NA & NA & $3.1(0.5-6.25)$ & RVF; HRS \\
\hline $56 \%$ & NA & $2.2(0.7-3.5)$ & RVF; CC; Sepsis \\
\hline NA & NA & $\begin{array}{l}\text { Up to } 4.9 \\
\text { years }\end{array}$ & NA \\
\hline $12(63 \%)$ & $8(43 \%)$ & $2.3 \pm 2.3$ & Sepsis \\
\hline $69 \%$ & $35 \%$ & Up to 19 years & \\
\hline NA & NA & NA & RVF \\
\hline $75 \%$ & NA & NA & RVF \\
\hline $74 \%$ & NA & $2 \pm 1.5$ & RVF; LF \\
\hline NA & NA & $2(0.6-4.2)$ & RVF \\
\hline
\end{tabular}

Data are mean \pm S.D., median (25-75th percentile), absolute (\%).

${ }^{a}$ After 2000; 'bingle centre series at different time points 
Table 4 Factors considered in selection of the patient for valve surgery.

\begin{tabular}{ll}
\hline Allocation & Risk \\
\hline Patient & Older age \\
& Gender \\
& Weight loss/low BMI (inc trend) \\
& Advanced symptom status \\
& Limited physical fitness \\
Risk factors & Hypertension \\
& Diabetes mellitus \\
& Smoking status \\
Co-morbidity & Cerebrovascular disease \\
& Peripheral vascular disease \\
& Chronic lung disease \\
& Chronic kidney disease \\
& Active carcinoid syndrome \\
& Disease progression \\
Disease status & Duration of somatostatin analogue therapy \\
& Prognosis, including options for further NET therapy \\
& Number, severity, location of valves affected \\
& Atrial communication \\
& RV size and function \\
Procedure details & LV size and function \\
& Coronary artery disease \\
& Pulmonary pressure
\end{tabular}

Assessment

Clinical records

NYHA

MLHF

Cardiopulmonary exercise test

24-hour ABP

$\mathrm{HbA} 1 \mathrm{C}$

Carotid Doppler

Lung function tests

Estimated GFR

Symptoms, urine 24-h 5HIAA

CT thorax, abdomen, pelvis (serial)

Cancer behaviour - indolent or rapid progression Echocardiography

Contrast echocardiography

CMR

CMR

Invasive angiography

$\mathrm{RHC}$

The above assessments are performed during admission and form part of the multidisciplinary data collected for review. Other factors and specialist opinions, for example in patients with retroperitoneal spread of NET leading to ureteric obstruction, would be invited to contribute.

replaced leading to symptomatic improvement - but risk is high and the physical condition of the patient taken on for multiple valve surgery must otherwise be excellent (47). Bioprosthetic valve replacements are chosen in preference to mechanical valves, as these mean the patient can avoid long-term anticoagulation, are at lower risk of valve thrombosis in the right heart, and have a better haemodynamic profile (48). Furthermore, consistent with the European Society of Cardiology guidelines, the choice of a bioprosthetic valve is also based on the consideration that the life expectancy of the NET patient with CHD is likely to be lower than the expected durability of the valve (49). Valves commonly used in practice include the Carpentier Edwards Perimount stented bovine prosthesis and the Hancock II porcine prosthesis, both of which have excellent longterm durability with rates of structural valve degeneration below $2 \%$ at 10 years and $15 \%$ at 20 years in left heart disease (50). PV replacement often requires patching of the pulmonary artery with bovine pericardium, as an adequate annulus size is critical to minimise afterload on the RV following surgery. Coronary artery by-pass grafting is performed in a minority of patients, limited to those with major epicardial stenosis $>70 \%$ (33). Surgery to the TV risks damage to the conduction system and the subsequent implantation of a permanent pacing wire through a functioning TV replacement is a disaster in CHD patients, so our practice to-date has been implantation of epicardial wires at the time of operation. This has the disadvantage that subsequent imaging follow-up has to be restricted to echocardiography, since CMR carries undefined risk and may not produce adequate image quality for analysis (51).

\section{Recommendations on surgery for CHD:}

1. Valve replacement should be performed in symptomatic patients with severe CHD.

2. Valve replacement should be performed in asymptomatic patients with severe CHD who have evidence of progressive ventricular dilatation or impaired ventricular function.

3. Any patient undergoing surgery on any valve for CHD should be tested for a patent foramen ovale and if present, this should be closed at time of operation.

4. Valve replacement should not be performed in patients with life expectancy of less than 12 months and should be delayed in those pending control of active carcinoid syndrome or reversal of a catabolic state.

5. Bioprosthetic (xenograft) valves should be used.

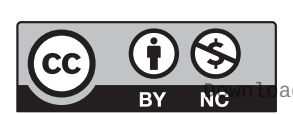

This work is licensed under a Creative Commons Attribution-NonCommercial 4.0 International License. ded from Bioscientifica.com at 04/26/2023 09:01:44AM via free access 
6. Surgery should be performed that minimises any requirement for implantation of transvalvar pacing wires, including prophylactic implantation of epicardial wires.

\section{Peri-operative and post-surgical care}

A major factor in terms of optimising outcome from valve surgery is the involvement throughout the patient pathway of Cardiothoracic Anaesthetists experienced in dealing with CS and patients with NET. The details of management in the peri-operative phase are outlined in Supplementary data 1 (see section on supplementary data given at the end of this article). Following surgery, all patients are returned to a specialist Cardiac Intensive Care Unit (ICU). Patients receive an octreotide infusion that is started before induction and is continued until the patient is haemodynamically stable and off inotropes. At the time of operation whilst the right atrium is still open, a pulmonary artery catheter is passed through the TV and PV into the right pulmonary artery for monitoring of cardiac output on ICU. This helps to guide inotropic and vasopressor support postoperatively. The patients are weaned from the ventilator and extubated as soon as it is clinically appropriate, since ventilation increases afterload on the RV and can further hinder contractility.

From the ICU, the patients are stepped down to a specialist Cardiothoracic Surgical ward for daily postoperative review, including regular physiotherapy and NET team assessment. Patients following surgery for CHD with bioprosthetic valve replacements are routinely commenced on warfarin anti-coagulation for 6 months, depending on risk assessment of bleeding, with the aim of minimising formation of microthrombi and preventing structural valve degeneration (49). Although there is evidence that non-vitamin $\mathrm{K}$ oral anticoagulants are superior to warfarin for the prevention of stroke and systemic embolism in non-valvar atrial fibrillation, only retrospective analyses have been performed in patients with atrial fibrillation and valve disease, including bioprosthetic valve replacements. While meta-analyses of these retrospective data suggest equivalent outcomes in terms of stroke and systemic embolism to warfarin, there are not data on the relevant efficacy for prevention of structural valve disease (52). Warfarin therefore continues to be used for this indication. Thereafter, patients are continued lifelong on aspirin $75 \mathrm{mg}$ od to reduce the recognised risk of early valve thrombosis and failure (34).
A formal baseline echocardiogram following surgery is essential against which to compare future studies to detect structural valve deterioration and complications. This sometimes may be performed within the surgical stay but study within 6-8 weeks is ideal to ensure optimal image quality (53).

\section{Follow-up}

All patients require lifelong follow-up by a cardiologist specialising in NET after valve surgery for CHD to detect early deterioration in prosthetic function, altered ventricular function or progressive disease of another heart valve (49). While this is consistent with current guidelines for the post-operative management of patients with all valve disease, this is particularly important in those with CHD. Given the unpredictable progression of CHD, our practice is for clinical assessment on a 6-monthly basis, with echocardiography performed on an annual basis to track change in ventricular function, increase in replacement valve velocities and the development of new valve lesions. A major risk for right heart valve replacements is valve thrombosis, although abrupt valve failure is uncommon. More usual is a gradual, asymptomatic serial increase in velocity in the absence of regurgitation, with velocities increasing above those performed on a routine pre-discharge echocardiogram (54). Even if asymptomatic, further investigation is warranted, although transoesophageal imaging is often required to determine change in leaflet thickness, mobility, and visualisation of thrombus. Multidetector gated CT may also be used as there is evidence this may be more sensitive (55). A second risk for patients following valve replacement for CHD is that of recurrent disease (34). Efforts have to be made to minimise CS by optimising control of NET (56). Under these circumstances, re-do valve surgery makes peri-operative risk unpalatable in many cases, although percutaneous valve-in-valve replacements can offer good clinical outcomes (57). Thirdly, patients with bioprosthetic valve replacements for CHD are at increased risk of infective endocarditis, particularly if immunocompromised, and serial reminders are given regarding the need for regular dental assessment and good dental hygiene throughout follow-up. Antibiotic prophylaxis should be considered for high-risk procedures in CHD patients with prosthetic valves, including dental procedures involving manipulation of the gingival or periapical region of the teeth or manipulation of the oral mucosa (58).

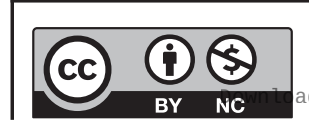


Recommendations on post-surgical care in CHD:

1. Peri-operative, intensive and post-surgical care requires highly specialised care from members of the whole multidisciplinary team with expertise in CHD.

2. CHD patients with bioprosthetic valves should be anti-coagulated with warfarin for 6 months and should remain lifelong on an anti-platelet agent thereafter.

3. Transthoracic echocardiography should be performed within 6-8 weeks of discharge following valve replacement.

4. All patients following valve replacement for CHD require regular review at 6-monthly intervals, with echocardiography performed on an annual basis.

5. Increased transvalvar velocities or de novo regurgitation through bioprosthetic valves should prompt consideration of structural valve deterioration and consideration of re-introduction of anticoagulation.

\section{Nursing care}

NET clinical nurse specialists (CNSs) have comprehensive expertise in managing all aspects of patient care and provide the 'bigger picture'. Their role as a 'key worker' facilitates care by the large multi-disciplinary team (59). The NET CNSs monitor patients for worsening of CS, development of CHD and can rapidly identify emerging clinical issues by being an immediate, accessible resource for the patient. They also focus on the holistic management of patients. Onset of CHD can lead to increased fatigue, and the psychological impact of CHD can be distressing for both patients and families. Effective and timely communication with the patient and family ensures they are well informed, which reduces stress and anxiety for the patient and family (60). Patients allocated with a CNS are more positive about the experience of their care, potentially because patients supported by a CNS receive holistic care that includes emotional and practical support as well as addressing physical needs. Often patients can build closer bonds with their CNS and ask questions which they may not want to ask their doctor (59).

Adopting a standardised approach to care and developing robust protocols and pathways helps with the induction of new members of the MDT. A key role for the CNS is in reinforcing patient safety by ensuring such protocols and pathways are well known and closely followed. The education of the wider care team regarding management of CS and CHD is a further focus for the CNS, including development and dissemination of comprehensive Carcinoid Management Guidelines that are widely available and shared with referring teams, further providing guidance and support. The CNS provides specialist education and training to other professionals involved in patient care to facilitate effective clinical practice across the MDT disciplines.

As the CNSs have knowledge and insight into the entire patient pathway, they are often able to influence care at key stages within the patient journey. This is fundamental to appreciation of the role of the CNS (61) and endorses their contribution to the development of policy and clinical guidelines. CNS participation in multiprofessional meetings ensures that nursing views are represented, but most importantly, they act as the patient advocate, keeping them at the heart of all we do (62).

Recommendations on nursing care in CHD:

1. Clinical nurse specialists act as key workers representing the patient.

2. Clinical nurse specialists ensure holistic care.

3. Nursing staff provide accessible education to both the patient and staff about neuroendocrine tumours, carcinoid syndrome and CHD.

\section{Prognosis and research needs}

Although NETs are generally considered to have a benign course, patients with CHD do not live as long as those without CHD (19). Moreover, prognosis deteriorates according to the severity of the CHD (63). Although surgery provides an opportunity to improve symptom status and is thought to increase life expectancy, there are no effective medical therapies that prevent or inhibit progression of CHD. Further research is needed in this rare but complicated disease with adverse outcomes (Table 5). Firstly, the link between high circulating levels of 5-HT in NET and the development of CHD is supported by several animal models either involving the injection of primary NET tumour cells or direct administration of serotonin. Newer hormonal therapies like telotristat, which have been shown to drastically reduce serotonin levels may hold promise in altering disease course in CHD, although evidence in this regard is scant $(26,64)$. Despite this however, the development of CHD cannot be explained by the sole presence of high levels of vasoactive substances in the circulation as the incidence of $\mathrm{CHD}$ is highly variable in patients with similar levels of 5HIAA (65). Further work is therefore required to understand the pathogenesis of 
Table 5 Future research priorities in CHD.

\begin{tabular}{ll}
\hline Diagnosis & Frequency of biomarker measurement \\
& Identification of novel circulating biomarkers which identify pathological factors driving valvular disease for \\
& example, pro-fibrotic markers, markers of neovascularisation. \\
Identification of novel tracers in nuclear medicine imaging to identify early fibrotic changes in valves. \\
Role of telotristat in preventing or delaying progression of CHD \\
Predictors of RV function post-TVR \\
Predictors of peri-operative mortality \\
Identify novel medical therapies that will prevent or reverse the progressive valvulopathy. for example, \\
targeting pro-fibrotic pathways.
\end{tabular}

this condition, specifically to understand what are the potential co-factors that drive fibrosis progression in the setting of high 5HIAA levels. Identification of these factors could help in patient stratification for treatment and help in the development of new therapeutic targets. Secondly, there is a need to better understand the risks and benefits of cardiothoracic surgery in CHD, and in predicting the outcome of patients with CHD to ensure the best short and long-term outcomes for patients.

Recommendations for research:

1. Identification of key fibrogenic markers and pathways in the valve tissue and blood from patients with CHD to guide patient risk stratification and the development of new therapies.

2. Development of preclinical models that are more representative of the clinical context i.e. organoids with primary human tissue that can be used to test novel therapies.

3. Identification of novel tracers and nuclear medicine imaging to identify early fibrotic changes in valves.

4. Identification of clinical factors/scores that will predict RV function post-TVR and per-operative mortality in order to support improved patient selection for surgery.

\section{Conclusions}

The presence of heart disease in a patient with CS confers a significantly worse prognosis compared to those without valvular heart disease. Clinical presentation is often late, as adherence to regular screening with biomarkers and echocardiography is incomplete. In those presenting with symptomatic CHD, control of symptoms with careful fluid management and diuretic therapy can help initially but valve replacement is the only treatment that can improve outcome. Surgery should always be considered regardless of metastatic disease, but peri-operative risk remains significant. Under these circumstances, optimal care is provided by close collaboration across multiple sub-specialties in centres with experience in management.

\section{Supplementary data}

This is linked to the online version of the paper at https://doi.org/10.1530/ EC-19-0413.

\section{Declaration of interest}

The authors declare that there is no conflict of interest that could be perceived as prejudicing the impartiality of this review.

\section{Funding}

This work did not receive any specific grant from any funding agency in the public, commercial, or not-for-profit sector.

\section{Author contribution statement}

Each co-author has contributed to the writing, review, and correction of the manuscript.

\section{Acknowledgements}

The authors wish to acknowledge the support of University Hospital Birmingham Charity Fund in supporting the development of the Neuroendocrine service.

\section{References}

1 Halperin DM, Shen C, Dasari A, Xu Y, Chu Y, Zhou S, Shih YT \& Yao JC. Frequency of carcinoid syndrome at neuroendocrine tumour diagnosis: a population-based study. Lancet Oncology 201718 525-534. (https://doi.org/10.1016/S1470-2045(17)30110-9)

2 Davar J, Connolly HM, Caplin ME, Pavel M, Zacks J, Bhattacharyya S, Cuthbertson DJ, Dobson R, Grozinsky-Glasberg S, Steeds RP, et al. Diagnosing and managing carcinoid heart disease in patients with neuroendocrine tumors: an expert statement. Journal of the American College of Cardiology 201769 1288-1304. (https://doi.org/10.1016/j. jacc.2016.12.030)

3 Rutkovskiy A, Malashicheva A, Sullivan G, Bogdanova M, Kostareva A, Stensløkken KO, Fiane A \& Vaage J. Valve interstitial cells: the key to understanding the pathophysiology of heart valve calcification. Journal of the American Heart Association 20176 e006339. (https://doi.org/10.1161/JAHA.117.006339)

4 Liu AC, Joag VR \& Gotlieb AI. The emerging role of valve interstitial cell phenotypes in regulating heart valve pathobiology. American Journal of Pathology 2007171 1407-1418. (https://doi.org/10.2353/ ajpath.2007.070251)

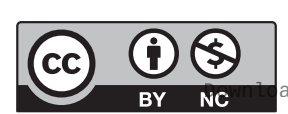

This work is licensed under a Creative Commons Attribution-NonCommercial 4.0 International License. ded from Bioscientifica,com at 04/26/2023 09:01:44AM 
5 Durbin AD \& Gotlieb AI. Advances towards understanding heart valve response to injury. Cardiovascular Pathology 200211 69-77. (https://doi.org/10.1016/s1054-8807(01)00109-0)

6 Liu AC, Joag VR \& Gotlieb AI. The emerging role of valve interstitial cell phenotypes in regulating heart valve pathobiology. American Journal of Pathology 2007171 1407-1418. (https://doi.org/10.2353/ ajpath.2007.070251)

7 Armstrong EJ \& Bischoff J. Heart valve development: endothelial cell signaling and differentiation. Circulation Research 200495 459-470. (https://doi.org/10.1161/01.RES.0000141146.95728.da)

8 Paruchuri S, Yang JH, Aikawa E, Melero-Martin JM, Khan ZA, Loukogeorgakis S, Schoen FJ \& Bischoff J. Human pulmonary valve progenitor cells exhibit endothelial/mesenchymal plasticity in response to vascular endothelial growth factor-A and transforming growth factor-beta2. Circulation Research 200699 861-869. (https:// doi.org/10.1161/01.RES.0000245188.41002.2c)

9 Yoder MC, Mead LE, Prater D, Krier TR, Mroueh KN, Li F, Krasich R, Temm CJ, Prchal JT \& Ingram DA. Redefining endothelial progenitor cells via clonal analysis and hematopoietic stem/progenitor cell principals. Blood 2007109 1801-1809. (https://doi.org/10.1182/ blood-2006-08-043471)

10 Tamura K, Jones M, Yamada I \& Ferrans VJ. Wound healing in the mitral valve. Journal of Heart Valve Disease 2000 9 53-63.

11 Desmouliere A, Badid C, Bochaton-Piallat ML \& Gabbiani G. Apoptosis during wound healing, fibrocontractive diseases and vascular wall injury. International Journal of Biochemistry and Cell Biology 199729 19-30. (https://doi.org/10.1016/s13572725(96)00117-3)

12 Grozinsky-Glasberg S, Grossman AB \& Gross DJ. Carcinoid heart disease: from pathophysiology to treatment - 'something in the way it moves'. Neuroendocrinology 2015101 263-273. (https://doi. org/10.1159/000381930)

13 Rajamannan NM, Caplice N, Anthikad F, Sebo TJ, Orszulak TA, Edwards WD, Tajik J \& Schwartz RS. Cell proliferation in carcinoid valve disease: a mechanism for serotonin effects. Journal of Heart Valve Disease 200110 827-831.

14 Bhattacharyya S, Davar J, Dreyfus G \& Caplin ME. Carcinoid heart disease. Circulation 2007116 2860-2865. (https://doi.org/10.1161/ CIRCULATIONAHA.107.701367)

15 Gardezi SKM, Myerson SG, Chambers J, Coffey S, d'Arcy J, Hobbs FDR, Holt J, Kennedy A, Loudon M, Prendergast A, et al. Cardiac auscultation poorly predicts the presence of valvular heart disease in asymptomatic primary care patients. Heart $2018 \mathbf{1 0 4}$ 1832-1835. (https://doi.org/10.1136/heartjnl-2018-313082)

16 Bhattacharyya S, Toumpanakis C, Caplin ME \& Davar J. Usefulness of N-terminal pro-brain natriuretic peptide as a biomarker of the presence of carcinoid heart disease. American Journal of Cardiology 2008102 938-942. (https://doi.org/10.1016/j.amjcard.2008.05.047)

17 Dobson R, Cuthbertson DJ, Jones J, Valle JW, Keevil B, Chadwick C, Poston GP \& Burgess MI. Determination of the optimal echocardiographic scoring system to quantify carcinoid heart disease. Neuroendocrinology 201499 85-93. (https://doi. org/10.1159/000360767)

18 Dobson R, Valle JW, Burgess MI, Poston GJ \& Cuthbertson DJ. Variation in cardiac screening and management of carcinoid heart disease in the UK and Republic of Ireland. Clinical Oncology 201527 741-746. (https://doi.org/10.1016/j.clon.2015.06.016)

19 Pellikka PA, Tajik AJ, Khandheria BK, Seward JB, Callahan JA, Pitot HC \& Kvols LK. Carcinoid heart disease. Clinical and echocardiographic spectrum in 74 patients. Circulation $1993 \mathbf{8 7}$ 1188-1196. (https://doi.org/10.1161/01.cir.87.4.1188)

20 Bhattacharyya S, Toumpanakis C, Burke M, Taylor AM, Caplin ME \& Davar J. Features of carcinoid heart disease identified by 2- and 3-dimensional echocardiography and cardiac MRI. Circulation: Cardiovascular Imaging 20103 103-111. (https://doi.org/10.1161/ CIRCIMAGING.109.886846)
21 Jahagirdar V, Kamal A, Steeds R \& Ayuk J. Metastatic small bowel neuroendocrine tumour with bilateral carcinoid heart disease. BMJ Case Reports 20162016 bcr2015213693. (https://doi.org/10.1136/ bcr-2015-213693)

22 Dobson R, Burgess MI, Valle JW, Pritchard DM, Vora J, Wong C, Chadwick C, Keevi B, Adaway J, Hofmann U, et al. Serial surveillance of carcinoid heart disease: factors associated with echocardiographic progression and mortality. British Journal of Cancer 2014111 1703-1709. (https://doi.org/10.1038/bjc.2014.468)

23 Møller JE, Connolly HM, Rubin J, Seward JB, Modesto K \& Pellikka PA. Factors associated with progression of carcinoid heart disease. New England Journal of Medicine 2003348 1005-1015. (https://doi.org/10.1056/NEJMoa021451)

24 Bhattacharyya S, Toumpanakis C, Chilkunda D, Caplin ME \& Davar J. Risk factors for the development and progression of carcinoid heart disease. American Journal of Cardiology 2011107 1221-1226. (https://doi.org/10.1016/j.amjcard.2010.12.025)

25 Sandmann H, Pakkal M \& Steeds R. Cardiovascular magnetic resonance imaging in the assessment of carcinoid heart disease. Clinical Radiology 200964 761-766. (https://doi.org/10.1016/j. crad.2008.10.013)

26 Pavel M, Gross DJ, Benavent M, Perros P, Srirajaskanthan R, Warner RRP, Kulke MH, Anthony LB, Kunz PL, Hörsch D, et al. Telotristat ethyl in carcinoid syndrome: safety and efficacy in the TELECAST phase 3 trial. Endocrine-Related Cancer 201825 309-322. (https://doi.org/10.1530/ERC-17-0455)

27 Bernheim AM, Connolly HM, Rubin J, Møller JE, Scott CG, Nagorney DM \& Pellikka PA. Role of hepatic resection for patients with carcinoid heart disease. Mayo Clinic Proceedings $2008 \mathbf{8 3}$ 143-150. (https://doi.org/10.4065/83.2.143)

28 Arends J, Bachmann P, Baracos V, Barthelemy N, Bertz H, Bozzetti F, Fearon K, Hutterer E, Isenring E, Kaasa S, et al. ESPEN guidelines on nutrition in cancer patients. Clinical Nutrition 201736 11-48. (https://doi.org/10.1016/j.clnu.2016.07.015)

29 Glazer ES, Stanko K, Ong ES \& Guerrero MA. Decreased inpatient mortality in obese patients with abdominal nets. Endocrine Practice 201420 1-20. (https://doi.org/10.4158/EP14203.OR)

30 Mamerow MM, Mettler JA, English KL, Casperson SL, ArentsonLantz E, Sheffield-Moore M, Layman DK \& Paddon-Jones D. Dietary protein distribution positively influences 24 -h muscle protein synthesis in healthy adults. Journal of Nutrition 2014144 876-880. (https://doi.org/10.3945/jn.113.185280)

31 Shah T \& Caplin M. Endocrine tumours of the gastrointestinal tract. Biotherapy for metastatic endocrine tumours. Best Practice and Research: Clinical Gastroenterology 200519 617-636. (https://doi. org/10.1016/j.bpg.2005.02.012)

32 Nickenig G, Weber M, Schueler R, Hausleiter J, Nabauer M, von Bardeleben RS, Sotiriou E, Schafer U, Deuschl F, Kuck KH, et al. 6-month outcomes of tricuspid valve reconstruction for patients with severe tricuspid regurgitation. Journal of the American College of Cardiology 201973 1905-1915. (https://doi.org/10.1016/j. jacc.2019.01.062)

33 Edwards NC, Yuan M, Nolan O, Pawade TA, Oelofse T, Singh H, Mehrzad H, Zia Z, Geh JI, Palmer DH, et al. Effect of valvular surgery in carcinoid heart disease: an observational cohort study. Journal of Clinical Endocrinology and Metabolism 2016101 183-190. (https://doi. org/10.1210/jc.2015-3295)

34 Nguyen A, Schaff HV, Abel MD, Luis SA, Lahr BD, Halfdanarson TR \& Connolly HM. Improving outcome of valve replacement for carcinoid heart disease. Journal of Thoracic and Cardiovascular Surgery 2019158 99-107.e2. (https://doi.org/10.1016/j.jtcvs.2018.09.025)

35 Mokhles P, van Herwerden LA, de Jong PL, de Herder WW, Siregar S, Constantinescu AA, van Domburg RT \& Roos-Hesselink JW. Carcinoid heart disease: outcomes after surgical valve replacement. European Journal of Cardio-Thoracic Surgery 201241 1278-1283. (https://doi.org/10.1093/ejcts/ezr227)

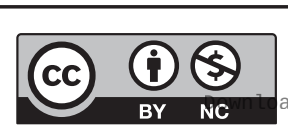

This work is licensed under a Creative Commons Attribution-NonCommercial 4.0 International License. ded from Bioscientifica.com at 04/26/2023 09:01:44AM 
36 Connolly HM, Schaff HV, Abel MD, Rubin J, Askew JW, Li Z, Inda JJ, Luis SA, Nishimura RA \& Pellikka PA. Early and late outcomes of surgical treatment in carcinoid heart disease. Journal of the American College of Cardiology 201566 2189-2196. (https://doi.org/10.1016/j. jacc.2015.09.014)

37 Robiolio PA, Rigolin VH, Harrison JK, Lowe JE, Moore JO, Bashore TM \& Feldman JM. Predictors of outcome of tricuspid valve replacement in carcinoid heart disease. American Journal of Cardiology 199575 485-488. (https://doi.org/10.1016/s0002-9149(99)80586-4)

38 Connolly HM, Nishimura RA, Smith HC, Pellikka PA, Mullany CJ $\&$ Kvols LK. Outcome of cardiac surgery for carcinoid heart disease. Journal of the American College of Cardiology 199525 410-416. (https://doi.org/10.1016/0735-1097(94)00374-y)

39 Castillo JG, Filsoufi F, Rahmanian PB, Anyanwu A, Zacks JS, Warner RRP \& Adams DH. Early and late results of valvular surgery for carcinoid heart disease. Journal of the American College of Cardiology 200851 1507-1509. (https://doi.org/10.1016/j. jacc.2007.12.036)

40 Bhattacharyya S, Raja SG, Toumpanakis C, Caplin ME, Dreyfus GD \& Davar J. Outcomes, risks and complications of cardiac surgery for carcinoid heart disease. European Journal of Cardio-Thoracic Surgery 201140 168-172. (https://doi.org/10.1016/j.ejcts.2010.10.035)

41 Komoda S, Komoda T, Pavel ME, Morawietz L, Wiedenmann B, Hetzer R \& Lehmkuhl HB. Cardiac surgery for carcinoid heart disease in 12 cases. General Thoracic and Cardiovascular Surgery 201159 780-785. (https://doi.org/10.1007/s11748-010-0758-9)

42 Kuntze T, Owais T, Secknus MA, Kaemmerer D, Baum R \& Girdauskas E. Results of contemporary valve surgery in patients with carcinoid heart disease. Journal of Heart Valve Disease 201625 356-363.

43 Mujtaba SS \& Clark S. Carcinoid heart disease: early outcomes after surgical valve replacement in nine patients. Heart Surgery Forum 2018 21 E040-E043. (https://doi.org/10.1532/hsf.1855)

44 Yong MS, Kong G, Ludhani P, Michael M, Morgan J, Hofman MS Hicks RJ \& Larobina M. Early outcomes of surgery for carcinoid heart disease. Heart, Lung and Circulation 2019 [epub]. (https://doi. org/10.1016/j.hlc.2019.05.183)

45 van Wissen J, Bakker N, Heus C \& Houdijk APJ. Preoperative nutrition in elderly patients and postoperative outcome. In Diet and Nutrition in Critical Care, pp. 741-752. Eds R Rajendram, VR Preedy \& VB Patel. New York, NY, USA: Springer, 2015.

46 Bachmann J, Ketterer K, Marsch C, Fechtner K, Krakowski-Roosen H, Büchler MW, Friess H \& Martignoni ME. Pancreatic cancerrelated cachexia: influence on metabolism and correlation to weight loss and pulmonary function. BMC Cancer 20099 255. (https://doi. org/10.1186/1471-2407-9-255)

47 Arghami A, Connolly HM, Abel MD \& Schaff HV. Quadruple valve replacement in patients with carcinoid heart disease. Journal of Thoracic and Cardiovascular Surgery 2010140 1432-1434. (https://doi. org/10.1016/j.jtcvs.2010.05.026)

48 Raja SG, Bhattacharyya S, Davar J \& Dreyfus GD. Surgery for carcinoid heart disease: current outcomes, concerns and controversies. Future Cardiology 20106 647-655. (https://doi. org/10.2217/fca.10.87)

49 Baumgartner H, Falk V, Bax JJ, De Bonis M, Hamm C, Holm PJ, Iung B, Lancellotti P, Lansac E, Rodriguez Muñoz D, et al. 2017 ESC/ EACTS guidelines for the management of valvular heart disease. European Heart Journal 201738 2739-2791. (https://doi.org/10.1093/ eurheartj/ehx391)

50 Johnston DR, Soltesz EG, Vakil N, Rajeswaran J, Roselli EE, Sabik III JF, Smedira NG, Svensson LG, Lytle BW \& Blackstone EH. Long-term durability of bioprosthetic aortic valves: implications from 12,569 implants. Annals of Thoracic Surgery 201599 1239-1247. (https://doi. org/10.1016/j.athoracsur.2014.10.070)

51 Padmanabhan D, Kella DK, Mehta R, Kapa S, Deshmukh A, Mulpuru S, Jaffe AS, Felmlee JP, Jondal ML, Dalzell CM, et al. Safety of magnetic resonance imaging in patients with legacy pacemakers and defibrillators and abandoned leads. Heart Rhythm 201815 228-233. (https://doi.org/10.1016/j.hrthm.2017.10.022)

52 Malik AH, Yandrapalli S, Aronow WS, Panza JA \& Cooper HA. Oral anticoagulants in atrial fibrillation with valvular heart disease and bioprosthetic heart valves. Heart 2019105 1432-1436. (https://doi. org/10.1136/heartjnl-2019-314767)

53 Chambers JB, Garbi M, Briffa N, Sharma V \& Steeds RP. Indications for echocardiography of replacement heart valves: a joint statement from the British Heart Valve Society and British Society of Echocardiography. Echo Research and Practice 20196 G9-G15. (https://doi.org/10.1530/ERP-18-0079)

54 Capodanno D, Petronio AS, Prendergast B, Eltchaninoff H, Vahanian A, Modine T, Lancellotti P, Sondergaard L, Ludman PF, Tamburino C, et al. Standardized definitions of structural deterioration and valve failure in assessing long-term durability of transcatheter and surgical aortic bioprosthetic valves: a consensus statement from the European Association of Percutaneous Cardiovascular Interventions (EAPCI) endorsed by the European Society of Cardiology (ESC) and the European Association for CardioThoracic Surgery (EACTS). European Journal of Cardio-Thoracic Surgery 201752 408-417. (https://doi.org/10.1093/ejcts/ezx244)

55 Pache G, Schoechlin S, Blanke P, Dorfs S, Jander N, Arepalli CD, Gick M, Buettner HJ, Leipsic J, Langer M, et al. Early hypo-attenuated leaflet thickening in balloon-expandable transcatheter aortic heart valves. European Heart Journal 201637 2263-2271. (https://doi. org/10.1093/eurheartj/ehv526)

56 Ridker PM, Chertow GM, Karlson EW, Neish AS \& Schoen FJ. Bioprosthetic tricuspid valve stenosis associated with extensive plaque deposition in carcinoid heart disease. American Heart Journal 1991121 1835-1838. (https://doi.org/10.1016/00028703(91)90045-j)

57 Khan JN, Doshi SN, Rooney SJ, Bhabra MS \& Steeds RP. Transcatheter pulmonary and tricuspid valve-in-valve replacement for bioprosthesis degeneration in carcinoid heart disease. European Heart Journal Cardiovascular Imaging 201617 114. (https://doi.org/10.1093/ ehjci/jev279)

58 Habib G, Lancellotti P, Antunes MJ, Bongiorni MG, Casalta JP, Del Zotti F, Dulgheru R, El Khoury G, Erba PA, Iung B, et al. ESC Guidelines for the management of infective endocarditis. European Heart Journal 201536 3075-3128. (https://doi.org/10.1093/eurheartj/ ehv319)

59 Read C. Workforce supplement: the benefits of specialist nurses. Health Service Journal 201527 February Supplement. (available at: https://www.hsj.co.uk/supplement-archive/workforce-supplemen t-the-benefits-of-specialist-nurses/5082712.article)

60 National Cancer Action Team. Clinical Nurse Specialists in Cancer Care; Provision, Proportion and Performance: A Census of the Cancer Specialist Nurse Workforce in England. London, UK: NHS National Cancer Programme, 2011. (available at: https://www.england.nhs.uk/imp rovement-hub/wp-content/uploads/sites/44/2017/11/Clinical-Nu rse-Specialists-in-Cancer-Care_Census-of-the-Nurse-Workforce_Eng2011.pdf)

61 Independent Cancer Taskforce. Achieving World Class Cancer Outcomes: A Strategy for England 2015-2020. London, UK: NHS England, 2015. (https://www.cancerresearchuk.org/sites/default/fi les/achieving_world-class_cancer_outcomes_-_a_strategy_for_englan d_2015-2020.pdf)

62 Royal College of Nursing. Specialist Nurses Make A Difference. RCN Policy Unit; Policy Briefing. London, UK: RCN, 2009. (available at: https://www.rcn.org.uk/about-us/policy-briefings/pol-1409)

63 Westberg G, Wängberg B, Ahlman H, Bergh CH, BeckmanSuurküla M \& Caidahl K. Prediction of prognosis by echocardiography in patients with midgut carcinoid syndrome. British Journal of Surgery 200188 865-872. (https://doi.org/10.1046/ j.0007-1323.2001.01798.x)

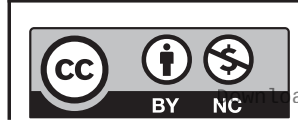


64 Zacks J, Lavine R, Ratner L \& Warner R. Telotristat etiprate appears to halt carcinoid heart disease. Neuroendocrinology 2016103 (Suppl 1) 90. (https://doi.org/10.1159/000448725)

65 Bhattacharyya S, Jagroop A, Gujral DM, Hayward C, Toumpanakis C, Caplin M, Mikhailidis DP \& Davar J. Circulating plasma and platelet 5-hydroxytryptamine in carcinoid heart disease: a pilot study. Journal of Heart Valve Disease 201322 400-407.
66 Oberg KE. The management of neuroendocrine tumours: current and future medical therapy options. Clinical Oncology 201224 282-293. (https://doi.org/10.1016/j.clon.2011.08.006)

67 Strosberg J, El-Haddad G, Wolin E, Hendifar A, Yao J, Chasen B, Mittra E, Kunz PL, Kulke MH, Jacene H, et al. Phase 3 trial of 177Lu-dotatate for midgut neuroendocrine tumors. New England Journal of Medicine 2017 376 125-135. (https://doi.org/10.1056/NEJMoa1607427)

Received in final form 1 November 2019

Accepted 11 November 2019

Accepted Preprint published online 11 November 2019 